\title{
Overexpression of glycosylated proteins in cervical cancer recognized by the Machaerocereus eruca agglutinin
}

\author{
Carlos Solórzano 1, 2, Miguel Ángel Mayoral², María de los Angeles Carlos ${ }^{3}$, \\ Jaime Berumen ${ }^{3}$, Jorge Guevara ${ }^{1}$, Francisco Raúl Chávez ${ }^{1}$, \\ Guillermo Mendoza-Hernández ${ }^{1}$, Concepción Agundis ${ }^{1}$, Edgar Zenteno ${ }^{1,2}$
}

\author{
${ }^{1}$ Laboratorio de Inmunología, Departamento de Bioquímica, Facultad de Medicina, UNAM, México \\ ${ }^{2}$ Centro de Investigaciones Multidisciplinarias UNAM-UABJO, Oaxaca, México \\ ${ }^{3}$ Departamento de Medicina Genómica, Hospital General de México, Secretaría de Salud, México
}

\begin{abstract}
In cervical cancer, glycosylation has been suggested as being involved in both its carcinogenesis and invasive capacity. In this work, we analyzed mucin type O-glycosylation in biopsies of invasive cervical cancer in FIGO stage II B through histochemistry using lectins specific for O-glycosidically linked glycans. Our results reveal that the lectin Machaerocereus eruca (MeA, specific for Gal in a Fuc $\alpha 1,2$ (GalNAc $\alpha 1,3)$ Gal $\beta 1,4$ ) showed increased recognition of tumoral cells and tumoral stroma tissue compared to other lectins with similar specificity; healthy cervical tissue was negative for MeA. Trypsin treatment of recognized tissues abolished MeA's recognition; moreover, interaction of MeA was inhibited with oligosaccharides from mucin. As demonstrated by Western blot of 2-D electrophoresis, MeA recognized ten glycoproteins in the range from 122 to $42 \mathrm{kDa}$ in cervical cancer lysates. The LC-ESI-MS/MS analysis of the MeAs' recognized peptides revealed that the latter matched mainly with the amino acid sequences of lamin $\mathrm{A} / \mathrm{C}$, vimentin, elongation factor 2 , keratin 1 , and beta actin. Our results suggest that MeA recognizes a complex of over-expressed O-glycosidically-linked proteins that play a relevant role in cervical cancer's invasive capacity. O-glycosylation participates in the disassembly of intercellular junctions favoring cancer progression. (Folia Histochemica et Cytobiologica 2012, Vol. 50, No. 3, 398-406)
\end{abstract}

Key words: lectins, Amaranthus leucocarpus, Machaerocereus eruca, cervical cancer, O-glycosylation, mucin

\section{Introduction}

Invasive cervical cancer constitutes $9.8 \%$ of cancers worldwide; it is also the commonest epidermoid cancer with a high mortality rate. The invasive capacity of cervical cancer is the most relevant feature of this cancer type. There is increasing evidence that glycosylation of proteins and glycolipids located on the

Correspondence address: E. Zenteno,

Departamento de Bioquímica,

Facultad de Medicina, UNAM, P.O. Box 70159, 04510, México;

fax: + 525556162419 ;

e-mail: ezenteno@servidor.unam.mx cellular surface or in the extracellular matrix play an important role in cellular recognition and in the organization of tissues and organs [1]. Moreover, altered carbohydrates expression is closely related to certain diseases and to the progression of neoplasms [2], such as in the human urinary tract [3], digestive tract [4], lung [5], and genital organs [6,7], among others. The specific role of tumor-associated glycoconjugates in diverse cell interactions is not clear; in some neoplasms, there are frequent alterations of cellular surface glycoconjugates due to incomplete synthesis, with or without accumulation of precursors, synthesis of neo-glycoconjugates, or structural reorganization/redistribution of glycoconjugates in cellular membranes $[1,8,9]$. It has been suggested that cell surface glyco- 
conjugates seem to be pivotal for oncogenic transformation, facilitating tumor cell migration and metastasis by affecting cell-cell and cell-matrix interactions $[2,10,11]$.

The participation of O-glycosidically-linked glycans (based on a Gal $\beta 1,3 \mathrm{GalNAc} \alpha \operatorname{Ser} / \mathrm{Thr}$ or GalNAc $\alpha$ Ser/Thr-containing core) in tumor cells adhesion and metastasis has been proposed based on the existence of O-glycans-mediated adhesion moieties in highly metastatic murine cells [12]. Lectins, due to their capacity to recognize carbohydrates, have been considered important tools for oligosaccharide characterization, as well as for isolation of cellular populations [13]. The active participation of O-glycosidically linked glycans in cervical dysplasia has been strongly suggested by the fact that lectins showing relatively similar sugar specificity for Gal or GalNAc, such as those from Amaranthus leucocarpus, Arachis hypogaea (PNA), or Dolichus biflorus (DBA), have shown differential staining of tissues according to cervical dysplasia progression $[14,15]$. The aim of this study was to identify the expression of mucin-type structures in invasive cervical cancer using lectins with well-known sugar specificity to elucidate the possible participation of O-glycosylated structures in cancer progression.

\section{Material and methods}

Tissues. Biopsies derived from patients with epidermoid cervical cancer $(\mathrm{n}=5)$ were classified as FIGO IIB according to the International Federation of Gynecology and Obstetrics system, and as T2b, N0, M0, according to the American Joint Committee on Cancer system. Normal cervical tissues $(\mathrm{n}=5)$ were derived from hysterectomies carried out for non-oncological reasons (used for comparison purposes) and obtained from the Departamento de Medicina Genomica, Hospital General de México, Secretaría de Salud, Mexico City, Mexico. The Ethics Surveillance Committee of the hospital authorized the use of tissue in this evaluated research protocol. All samples were obtained after informed consent from patients, and tissues were fixed in $4 \%$ phosphate-buffered paraformaldehyde and embedded in paraffin. The tissue specimens were diagnosed using standard histopathological criteria by experienced pathologists.

Lectins. The Amaranthus leucocarpus lectin (ALL; specific for GalNAc in Gal $\beta 1,3-$ GalNAc- $\alpha 1,0-\mathrm{Ser} / \mathrm{Thr}$ ) was purified by affinity chromatography [16]. Machaerocereus eruca agglutinin (isoform MeA-II; specific for $\mathrm{OH}$ - in $\mathrm{C} 4$ from $\mathrm{Gal}$ in the Fuc $\alpha 1,2$ (GalNAc $\alpha 1,3)$ Gal $\beta 1,4$ sequence from complex mucin structures) was purified from cactus stems by affinity chromatography on mucin-Sepharose 4B [17]. Arachis hypogaea agglutinin (PNA; specific for Gal in $\mathrm{Gal} \beta 1,3 \mathrm{GalNAc}$ or $\mathrm{Gal} \beta 1,4 \mathrm{GlcNAc}$ sequences in glycopro- teins or glycolipids) was purchased from EY Lab (San Mateo, CA, USA). Lectins were labeled with the N-hydroxysuccinimide ester of biotin from Pierce Chem. Co. (Rockford, IL, USA) at a label/protein ratio of 2:1 [18]. Oligosaccharides (containing $\mathrm{Gal}_{2}$ GlcNAc3Fuc1GalNac1GalNAcol) used for inhibition assays with MeA were purified from porcine stomach mucin after alkaline reductive treatment and FPLC purification as described in [19].

Hematoxylin and eosin stain (H\&E). The tissues stained with hematoxylin-eosin were observed through a Leica DM/ /LS microscope at $40 \times$, and photographed using images captured with a digital Leica DFC-300FX camera (Leica Microsystems Digital Imaging, Cambridge, UK) and processed with Leica Software IM1000 (Imagic Bildverarbeitung AG, Leica Microsystems, Heerbrugg, Switzerland).

Histochemistry. Sections (5- $\mu \mathrm{m}$ thick) were deparaffinized and re-hydrated according to conventional histological techniques. Then they were rinsed with a phosphate-buffered saline (PBS, $50 \mathrm{mM}$ sodium phosphate, $0.15 \mathrm{M} \mathrm{NaCl}, \mathrm{pH}$ 7.4). Unspecific binding sites were blocked by IgG-free $2 \%$ bovine serum albumin (BSA, Sigma, St Louis, MO, USA), for $30 \mathrm{~min}$. Afterwards, specimens were incubated for 10 min with $0.2 \%$ Triton X-100 in PBS, rinsed with $1 \mathrm{mM}$ $\mathrm{PBS} \mathrm{Ca}^{2+}$, and, then, tissue sections were incubated with biotinylated lectins (MeA and PNA, 1:100; ALL 1:200, as optimal dilutions) at $37^{\circ} \mathrm{C}$ in a humid-storage chamber for $2 \mathrm{~h}$. Slides were rinsed twice with $\mathrm{PBS}-\mathrm{Ca}^{2+}$ and incubated at $37^{\circ} \mathrm{C}$ with extravidin-fluorescein isothiocyanate (FITC; Sigma), dilution 1:60, in a dark humid-storage chamber for $1 \mathrm{~h}$, the slides were sealed with a DAPI-containing VectaShield mounting medium (Vector Labs, Burlingame, CA, USA) [20].

Trypsin treatment of tissues. Slides were deparaffinized and re-hydrated similarly as described for histochemistry and rinsed with PBS. Tissues were incubated with $2 \%$ trypsin (Gibco, Grand Island, NY, USA) in PBS at several time intervals (30 to $120 \mathrm{~min}$ ) at $37^{\circ} \mathrm{C}$ in a humidified chamber. Then, tissues were washed with PBS and incubated for 30 min with IgG-free $2 \%$ BSA and washed for 10 min with $0.2 \%$ Triton $\mathrm{X}-100$. Exhaustive rinses with PBS- $\mathrm{CaCl}_{2}$ were made before the specimens were incubated for $2 \mathrm{~h}$ with biotinylated lectins, as indicated.

Fluorescence microscopy. Slides were observed through a Leica DM/LS fluorescent microscope (Leica Microsystems, Wetzlar, Germany) with $10 \times, 20 \times, 40 \times, 63 \times$, and $100 \times$ objectives. Fluorochromes were visualized with their specific filters and analyzed in two channels: green for lectins and blue for nuclei. Images were captured with a Leica DFC-300FX digital camera (Leica) adapted to the microscope. The images were projected with a Leica IM1000 version 1.20 release-9 computer-based program (Leica Microsystems Digital Imaging, Cambridge, UK). 
Specificity of lectin labeling. To determine the specificity in the interaction of lectins with tissues, control assays were performed using lectins incubated previously with $100 \mathrm{mM}$ GalNAc and lactose, for ALL and PNA lectins, respectively, or $10 \mu \mathrm{M}$ oligosaccharides from porcine stomach mucin for MeA [19], prior to labeling the tissues.

Two-dimensional (2-D) polyacrylamide gel electrophoresis. Before electrophoresis, the cervical cancer tissues were lysed in a solution of PBS containing $1 \mu \mathrm{g} / \mathrm{ml}$ aprotinin-A, $1 \mu \mathrm{g} / \mathrm{ml}$ pepstatin, $2 \mu \mathrm{g} / \mathrm{ml}$ leupeptin, $2 \mathrm{mM}$ phenylmethylsulfonyl fluoride, and 1.0\% (v/v) Triton X-100 (lysis buffer), for $30 \mathrm{~min}$ at $4^{\circ} \mathrm{C}$, under shaking. Nuclei, cell debris, and mitochondria were removed by centrifugation, first for 10 $\mathrm{min}$ at $250 \times \mathrm{g}$ and then for $30 \mathrm{~min}$ at $18,000 \times \mathrm{g}$; the clear supernatant was used for 2-D electrophoresis assays. Isoelectric focusing was carried out as follows: the lysed tissues (90 $\mu \mathrm{g}$ of total protein) were treated with a 2D-Clean-Up kit (Amersham Biosciences). The protein pellet was resuspended and the final volume was adjusted to $125 \mu \mathrm{l}$ with rehydration buffer ( $8 \mathrm{M}$ urea, $2 \%$ CHAPS, $0.5 \%$ of IPG buffer, $\mathrm{pH} 4-7$, and $20 \mathrm{mM}$ DTT). The sample was used to rehydrate 7-cm immobilized, $\mathrm{pH} 4-7$, linear gradient strips (Immobiline DryStrips, GE Healthcare) for $16 \mathrm{~h}$ at room temperature (RT), following the manufacturer's instructions. Focusing started at $300 \mathrm{~V}(1 \mathrm{~h})$, increased to $1,000 \mathrm{~V}$ $(0.5 \mathrm{~h})$, and further increased to 5,000 V (2 h) in an Ettan IPGphor III Electrophoresis Unit (GE Healthcare). After focusing, the strips were equilibrated for $20 \mathrm{~min}$ in equilibrium buffer (2\% SDS, $50 \mathrm{mM}$ Tris- $\mathrm{HCl}, \mathrm{pH} 8.8,6 \mathrm{M}$ urea, $30 \%$ glycerol, $0.002 \%$ bromophenol blue, and $0.5 \%$ DTT). The strips were then overlaid on $12 \%$ SDS polyacrylamide gels and, after electrophoresis, proteins were transferred to Immobilon-P PVDF membranes (Millipore Corp, Billerica, MA, USA). Membranes were stained with Coomassie Brilliant Blue R-250 and used to perform lectin-blotting assays.

MeA-blotting assays. Proteins from the 2-D SDS-PAGE were transferred to PVDF membranes and incubated with $1 \mu \mathrm{g} / \mathrm{ml}$ of MeA-HRP in PBS containing $0.05 \%$ Tween 20 and 3\% BSA (PBS-TB) in the presence or absence of 100 $\mu \mathrm{g}$ stomach mucine oligosaccharides for $1 \mathrm{~h}$ at room temperature $\left(22 \pm 2^{\circ} \mathrm{C}\right)$, according to the method described by Towbin et al. [21]. After incubation, membranes were rinsed with PBS containing $0.05 \%$ Tween 20 (PBS-T) and MeA reactivity was revealed with $3 \mathrm{mg} / \mathrm{ml}$ of 3,3-diaminobenzidine in PBS-T and 30\% hydrogen peroxide diluted 1:1,000.

Analytical methods. Protein concentration was determined according to the Lowry procedure modified by Peterson, using bovine serum albumin as standard [22].

Nano LC-ESI-MS/MS. Protein spots from the lysed tissues and recognized by the lectin MeA after 2-D electrophore- sis were excised from the SDS-PAGE with a sterile scalpel. The gel pieces were washed with $50 \%(\mathrm{v} / \mathrm{v})$ acetonitrile in $25 \mathrm{mM}$ ammonium bicarbonate $(\mathrm{pH} 8.5)$ for 15 min twice to remove Coomassie dye. After dehydration with $100 \%$ $(\mathrm{v} / \mathrm{v})$ acetonitrile for $10 \mathrm{~min}$ at room temperature, the gel pieces were vacuum-dried and rehydrated with sequencing-grade modified trypsin (Promega, Madison, WI, USA) in $25 \mathrm{mM}$ ammonium bicarbonate $(\mathrm{pH} 8.5)$ at $37^{\circ} \mathrm{C}$ overnight. The in-gel tryptic digested samples were injected into an integrated nano-LC-ESI-MS/MS system (quadrupole/time of flight, Ultima API, Micromass, Manchester, UK). The injected samples were first trapped and desalted isocratically on an LC-Packing PepMap C18 $\mu$-pre-column cartridge (Dionex, Sunnyvale, CA, USA). After dissolving with $0.1 \%$ formic acid, the samples were loaded into an analytical C18 capillary column connected online to the mass spectrometer. Instrumental operation, data acquisition, and analysis were performed under the full control of Mass-Lynx 4.0 (Micromass). The 1-s survey scans were run over the mass range of $\mathrm{m} / \mathrm{z} 400$ to 2000 . The acquired peptide ions were analyzed with the Mascot program (www.matrixscience.com) using both NCBInr and EST databases. Parameters for the Mascot search were peptide mass tolerance of $1 \mathrm{Da}$; MS/MS ion mass tolerance of $1 \mathrm{Da}$, maximally one missed cleavage, and tryptic digestion. Variable modifications included methionine oxidation and cysteine carbamidomethylation. Only proteins with significant ion scores $(>62)$ were reported [23].

\section{Results}

\section{Analysis by light microscopy of cervical tissues}

In cervical tissues from healthy individuals, non-keratinized stratified epithelium, in proliferative phase, without alterations was identified in either epthelia or stroma (Figure 1A). All analyzed cervico-uterine cancer tissues depicted a loss of epithelial border within the stroma, many pleomorphic cells showing big nuclei, as well as loss of the nuclei/cytoplasm relation and infiltration of the stroma. In addition, inflammatory infiltrate with predominantly mononuclear and lymphocytic cells in the stromal region was observed (Figure 1E).

\section{Histochemistry with lectins}

In healthy tissues, the lectin PNA showed the capacity to recognize, with low intensity, the plasmatic membrane of epithelial cells from the superficial stratus. This lectin was not able to recognize epithelial cells of the basal or intermedial stratus, nor the cellular components of the extracellular matrix in the cervical stroma (Figure 1B). PNA in cervico-uterine can- 
cer tissue showed moderate reactivity to the plasmatic membrane from neoplasic cells that infiltrated the stroma; this lectin recognized some endothelial cells of blood vessels and, with moderate intensity, some components of the extracellular matrix from the tumoral stroma (Figure 1F).

In healthy tissues, the lectin ALL recognized with low or moderate capacity the plasmatic membrane of epithelial cells from the superficial stratus; this lectin did not recognize epithelial cells from the basal or intermediate stratus. No other components from the cellular or the extracellular cervical stroma were identified by this lectin (Figure 1C). As shown in Figure $1 \mathrm{G}$, in cervico-uterine cancer tissue, the lectin ALL showed low to intense reactivity toward the plasmatic membrane of tumoral cells; moreover, this lectin showed moderate reactivity toward the extracellular matrix and also to the vascular endothelium and adventitia of blood vessels.

In the cervix from healthy individuals, the lectin from the cactus, MeA, showed no reactivity toward any epithelial structure, cellular component, nor to the cervical stromal matrix (Figure 1D); whereas, as shown in Figure $1 \mathrm{H}$, this lectin showed intense positive reaction toward cells and stroma (Table 1), as well as low to moderate reactivity toward blood vessels endothelium in cervical tissues from cancer patients.

\section{Specificity of lectin labeling}

To determine the specificity in the interaction of lectins with tissues, control assays were performed using lectins incubated for $30 \mathrm{~min}$ with $100 \mathrm{mM}$ lactose for PNA or $100 \mathrm{mM}$ GalNAc for ALL to inhibit their interaction (not shown). Incubation of MeA with $10 \mu \mathrm{M}$ porcine stomach mucin oligosaccharides prior to adding the corresponding lectin to the tissues, completely inhibited MeA staining (Figure 2C); whereas Gal inhibited partially the interaction of MeA (Figure 2D). Other monosaccharides, such as $100 \mathrm{mM}$ Glc, Man, L-Fuc, GalNAc, and GlcNAc, failed to inhibit the positive labeling of the MeA lectin.

\section{Trypsin treatment of tissues}

Tissues from normal cervix and from cervico-uterine cancer were treated with trypsin at different time intervals. Control assays showed that the treatment with trypsin increased reactivity to PNA in all healthy and cancer tissues with an optimal 120-min treatment time (not shown). Healthy tissues remained negative for MeA after trypsin treatment (not shown). However, reactivity to MeA (Figure $3 \mathrm{~B}$ ) by cancer tissues diminished after $30 \mathrm{~min}$ of treatment with this protease
(Figure3C), compared to non-treated MeA positive tissues (Figure 3B); interestingly, after $120 \mathrm{~min}$ of trypsin treatment, reactivity to MeA was abolished (Figure 3D).

Immunoblotting with $M$. eruca agglutinin and Nano LC-ESI-MS/MS analysis

The 2-D electrophoresis of cervical cancer tissues revealed several spots within the range of $180-15 \mathrm{kDa}$. Cervical cancer tissues resolved by 2-D electrophoresis were evaluated for MeA binding (Figure 4A). Three different experiments were performed, and reactive MeA spots were considered positive only if they were represented in the three assays. As demonstrated by Western blot of 2-D electrophoresis from the cancer cervical lysate, MeA recognized a complex of ten glycoproteins in the range of 126 to $42 \mathrm{kDa}$ (Figure 4B). Control assays using MeA, previously incubated with $100 \mu \mathrm{M}$ of mucin oligosaccharides, showed no recognition of transferred glycoproteins (not shown). Nano LC-ESI-MS/MS analysis identified that six of the recognized glycoproteins showed significant ion scores $(>62)$ corresponding to lamin $\mathrm{A} / \mathrm{C}$, vimentin, elongation factor 2 , keratin 1 , and the 42-kDa beta actin (Table 2).

\section{Discussion}

Mucin type O-glycosylation is a postranslational modification of proteins and lipids performed in the Golgi apparatus [1,2]. Alterations in O-glycosylation of proteins in cell surfaces can originate in disorders of cellular function, as well as in cell transformation and tumoral differentiation. Subtle modifications in the mucin-type O-glycosylation pattern could be considered for the diagnosis or prognosis of cervical precancerous stages [24]. O-glycosylation in cervical intraepithelial dysplasia (CIN) at different stages of differentiation shows different recognition patterns by O-glycan-specific lectins [14], suggesting the active participation of O-glycosidically linked structures in cancer progression. In this work, we analyzed mucin type O-glycosylation in biopsies of invasive cervical cancer in FIGO stage II B through histochemistry using lectins specific for O-glycosidically linked glycans.

Mucin-type O-glycosylation is initiated by a large family of UDP-GalNAc: polypeptide GalNAc-transferases that adds GalNAc to selected Ser and Thr residues. Further assembly of O-glycan chains involves different biosynthetic pathways. The O-glycosidically linked glycans present in glycoproteins could be initiated by mucin-type core-1 (Gal $\beta 1,3 \mathrm{GalNac}-\mathrm{Ser} /$ $/ \mathrm{Thr}$, or T antigen) or by UDP-GalNAc $\beta 1,3 \mathrm{Gal}$-trans- 

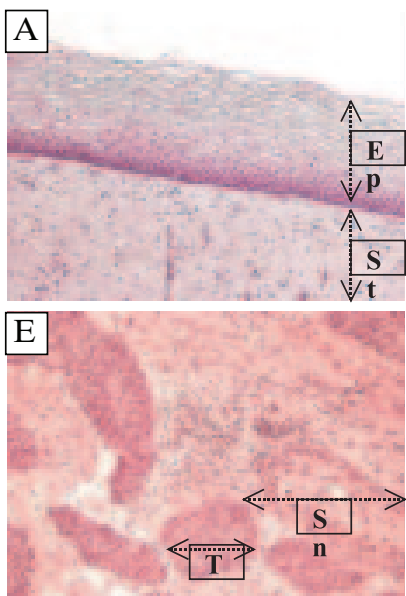
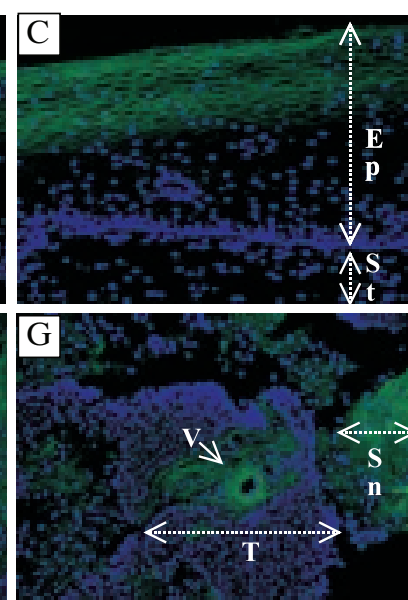
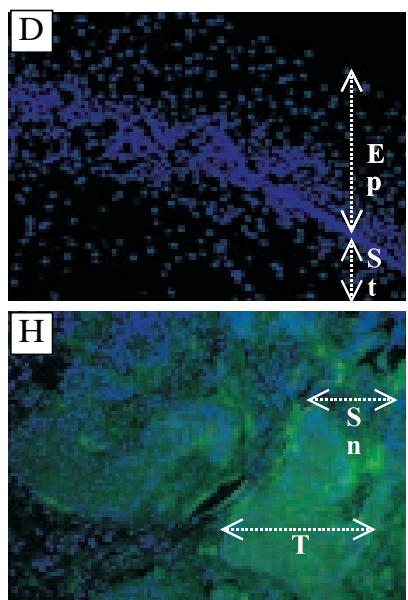

Figure 1. Lectin histochemistry of human normal cervical tissues and from patients with cervico-uterine cancer. A. H\&E of cervical tissue from healthy individuals without alterations in either epthelia (dotted arrow Ep) or stroma (dotted arrow St). B. Healthy cervical tissue showed positive reactivity to PNA in the plasmatic membrane of epithelial cells from the superficial stratus. C. ALL recognized with moderate capacity the plasmatic membrane from epithelial cells from the superficial stratus. D. Reactivity to MeA was negative. E. H\&E of cervico-uterine cancer tissues depicted loss of epithelial border within the stroma (dotted arrow T), showing pleomorphic cells and infiltration of the stroma (dotted arrow Sn). F. In cervicouterine cancer tissues, PNA showed moderate reactivity to the plasmatic membrane from neoplasic cells that infiltrated the stroma and the extracellular matrix from the tumoral stroma (solid arrow V). G. ALL showed low to intense reactivity to the plasmatic membrane of tumoral cells and the extracellular matrix and also to the vascular endothelium and adventitia of blood vessels (solid arrow V). H. MeA showed positive reaction toward cells and stroma, as well as in the stromal zone. Biotin labeled lectins were revealed with extravidin-FITC and the nucleus was observed with DAPI staining (blue stain) $40 \times$
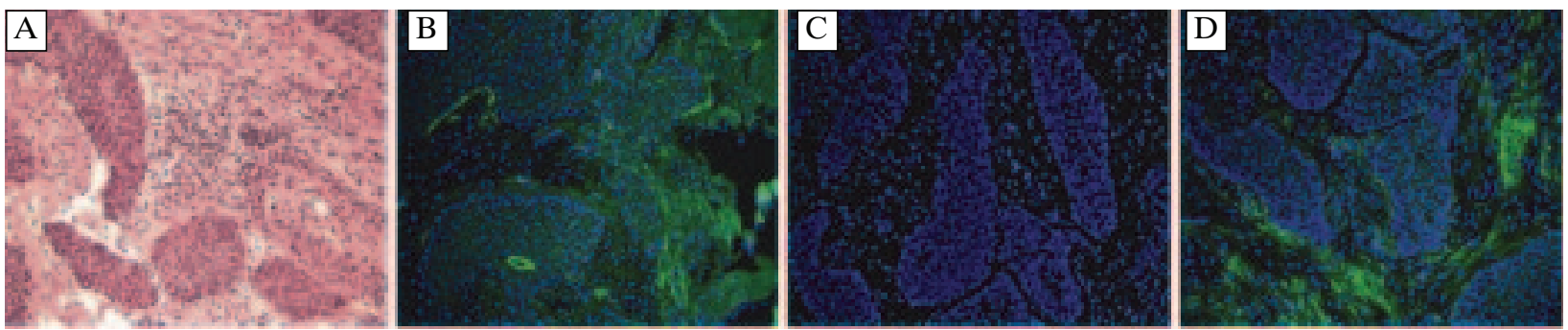

Figure 2. Specificity of MeA staining for cervico-uterine cancer tissues. A. H\&E of cervico-uterine cancer tissues, B. MeA staining, C. MeA incubated previously with $100 \mu \mathrm{M}$ porcine stomach mucin oligosaccharides, and D. MeA incubated with $100 \mathrm{mM}$ Gal. Other carbohydrates that showed no effect on MeA interaction were $100 \mathrm{mM}$ Glc, Man, L-Fuc, GalNAc, and GlcNAc. The carbohydrates were incubated with the lectin for $30 \mathrm{~min}$ before histochemistry assays. Nuclei (in blue) were stained with DAPI $(40 \times)$
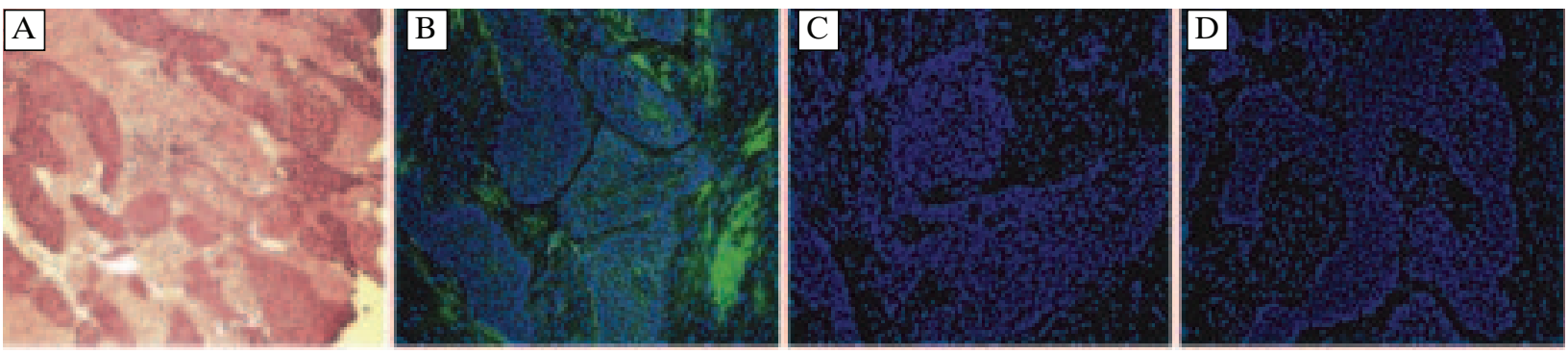

Figure 3. Effect of trypsin treatment on tissues before addition of FITC-labeled MeA. (A) HE-control assays (B) Histochemistry with FITC-labeled MeA; tissues were treated with trypsin for (C) 30, and (D) 120 min before addition of the MeA lectin. Nuclei (in blue) were stained with DAPI $(40 \times)$ 
ferase activity that could be converted, in turn, to complex-type core-2 by UDP-GlcNAc: Gal $\beta 1,3$ GalNAc $\alpha 1$, 6GlcNAc-transferase. They could also form mucintype core- 3 by UDP-GlcNAc:GalNAc $\alpha 1,3$ GlcNActransferase [25] or more complex structures, such as core- 8 by core- $8-\alpha 3 \mathrm{Gal}$-transferase [26]. The lectin PNA showed moderate reactivity to the plasmatic membrane from neoplasic cells that infiltrated the stroma. PNA recognizes the hydroxyl group on C-4 of the terminal galactose in the $\mathrm{T}$ antigen, as well as in lactosamine ( $\mathrm{Gal} \beta 1,4 \mathrm{GlcNAc})$ residues in N-glycans from glycoproteins or from glycolipids [20, 27]. ALL recognizes GalNAc in the T- or the Tn-antigen [28]. The lectin ALL showed low to intense reactivity to the plasmatic membrane of cervical cancer cells and moderate reactivity toward the extracellular matrix. Expression of the mucin type core-1, identified by ALL, is highly expressed in CIN II dysplasia compared to CIN I and CIN III or, as shown in this work, in cervical cancer, suggesting the active participation of glycosyl-transferases that render complex-type glycosylation during invasiveness [14]. The ability of lectins to bind carbohydrates depends on their 3-D structure $[29,30]$ and on their capacity to detect subtle variations in the conformation of carbohydrate structures from the cell surfaces [31]. This ability could be

Table 1. Description of lectin reactivity

\begin{tabular}{|l|c|c|c|}
\hline \multirow{2}{*}{ Lectin labeling of human cervical tissues and cervical cancer } \\
\hline \multirow{2}{*}{ Tissues } & \multicolumn{3}{|c|}{ Lectin } \\
\cline { 2 - 4 } & PNA & ALL & MeA \\
\hline Normal cervical tissues & & & \\
Epithelial zones & & & \\
Superficial & + & + & - \\
Intermedial & - & - & - \\
Basal & - & - & - \\
Stromal zones & - & - & - \\
\hline Cervical cancer & & & \\
Epithelioid zones & ++ & + & +++ \\
Stroma zones & + & + & ++ \\
\hline
\end{tabular}
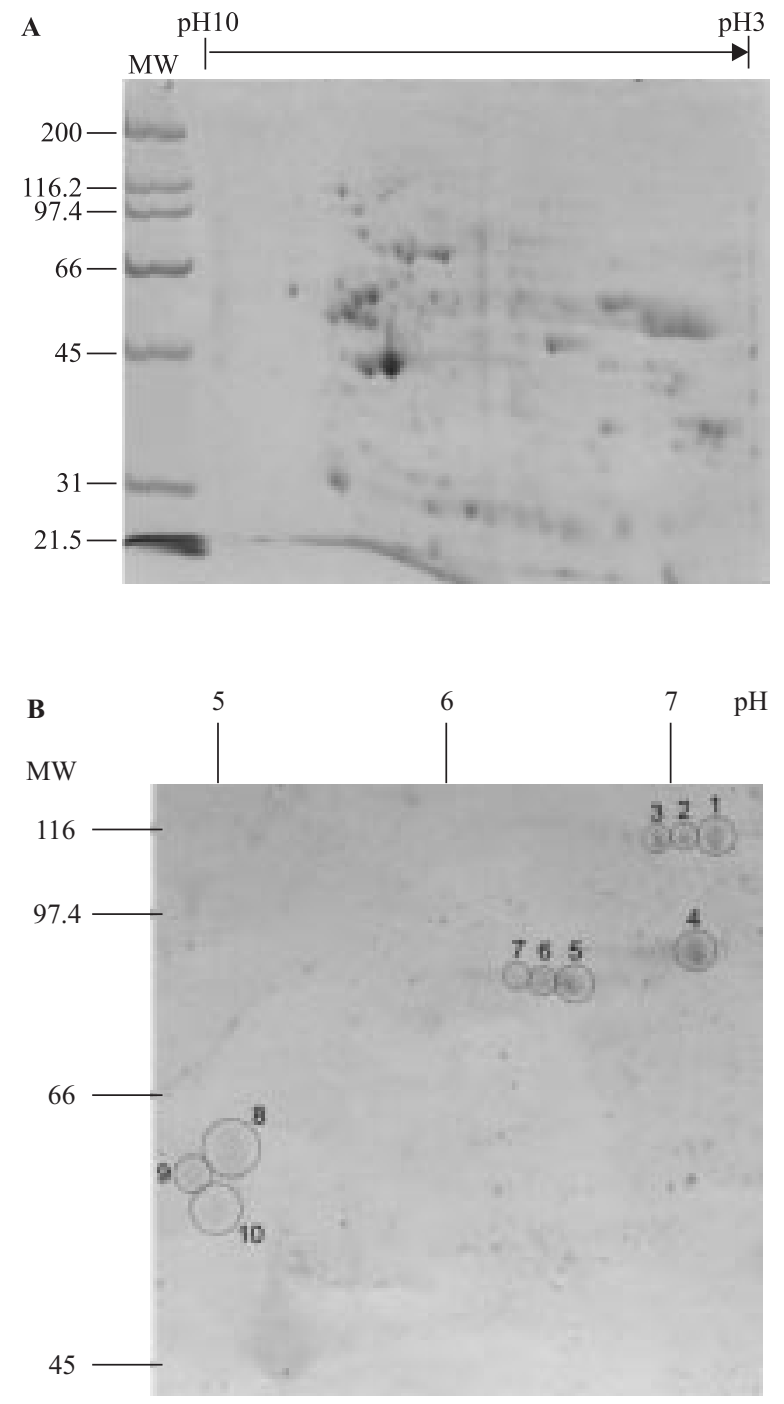

Figure 4. Ligand blotting assay of cervico-uterine cancer lysate tissue resolved by $2-\mathrm{D}$ electrophoresis.

(A) Cervico-uterine cancer cell lysate blotted onto PVDF membrane and stained with Coomassie blue. (B) Detail of the ligand blotting of cervico-uterine cancer cells lysate incubated with MeA. Only protein spots that reacted with MeA consistently over three experiments are circled. The arrows in panel A indicate the position of MeA positive spots

Table 2. MeA WB-bound proteins from cervico-uterine cancer identified in LC Ms/Ms

\begin{tabular}{|l|c|l|c|c|c|}
\hline $\begin{array}{l}\text { NCBI } \\
\text { Accession }\end{array}$ & $\begin{array}{c}\text { Spot* } \\
\text { No }\end{array}$ & Protein & $\begin{array}{c}\text { Theoretical } \\
\text { Mass (kDa) }\end{array}$ & $\begin{array}{c}\text { Peptides } \\
\text { matched }\end{array}$ & $\begin{array}{c}\text { Sequence } \\
\text { Coverage** }\end{array}$ \\
\hline gi $\mid 4503483$ & 4 & Elongation factor 2 & 96 & 16 & $25 \%$ \\
\hline gi| 119573383 & 5 & Lamin A/C & 88 & 15 & $23 \%$ \\
\hline gi $\mid 11935049$ & 8 & Keratin 1 & 66 & 4 & $17 \%$ \\
\hline gi $\mid 62414289$ & 9 & Vimentin & 54 & 13 & $64 \%$ \\
\hline gi $\mid 4501885528$ & 10 & Beta actin & 42 & 6 & $68 \%$ \\
\hline
\end{tabular}

Only proteins that showed significant ion scores $(>62)$ are indicated. $*$ MeA positive spot identified in Figure 2 A. $* *$ Represents the identity with the indicated protein 
explained by the variability in the size of the carbohydrate-recognition domain and the variability in quaternary association [28].

Our results showed that the lectin Machaerocereus eruca showed high capacity to recognize tumoral cells and tumoral tissue stroma, whereas healthy cervical tissue was negative for MeA. MeA interacts mainly with the Gal residues present in biantennary $\mathrm{O}$-glycans possessing the terminal trisaccharide Fuc $\alpha$ $1,2$ (GalNAc $\alpha 1,3) \mathrm{Gal} \beta 1,4$ in mucin with A+H blood group determinant [19]. Most of the patterns of peripheral/terminal glycosylation are polymorphic in humans and constitute histo-blood groups, among which we know the systems ABO, secretor, Lewis, $\mathrm{T}$, Tn and $\mathrm{P}$ [8]. These antigen determinants have been identified in most human epithelia [32] and it has been considered that $\mathrm{H}$-antigen-related structures confer a highly malignant phenotype and metastatic potential $[33,34]$.

The lectin MeA showed a higher capacity to specifically recognize cervical cancer tissues. The fact that trypsin treatment of tissues abolished the positive recognition of this lectin suggested that the MeA-receptor seems to be of glycoprotein nature, in contrast to PNA, which is also able to recognize glycosidicallylinked glycans to lipids [27]; for this reason, further characterization by Western blot and 2-D electrophoresis of MeA-recognized glycoproteins was performed. Our results suggest that, in the cervical cancer lysate, MeA recognizes a complex of several glycoproteins in the range of 126 to $49 \mathrm{kDa}$. Nano LC-ESI-MS/MS analysis identified that the MeA-recognized glycoproteins with high ion scores corresponded mainly to lamin $\mathrm{A} / \mathrm{C}$ and to vimentin, and with lower significance to the elongation factor (EF2), keratin 1, beta actin, and POTE ankyrin domain family member E. Lamin A has been shown to exert a functional link between the nuclear envelope and the cell surface functional extracellular matrix in aging and tumoral processes [35]. Lamin may also affect the extracellular matrix by the closely connected network of actin-lamin links; this link is affected usually by oncogenes and may play a role in nuclear envelope distortion and in the margin irregularity in tumoral processes [36]. Vimentin is a 58-kDa glycoprotein that has been considered as a relevant tumor marker in distinguishing primary endometrial adenocarcinomas from endocervical adenocarcinomas [37]. Immunofluorescent stainings of surgical specimens have indicated that cervical carcinoma progression and cell invasion is accompanied by vimentin and epidermal growth factor receptor overexpression [38]. Vimentin is a useful additional diagnostic marker in the assessment of problematic cervical glandular lesions; the expression of vimentin at the deep margin of some endocervical adenocarcinomas may be relevant to the process of tumor progression and invasion $[39,40]$. POTE has recently been found to be expressed in the majority of ovarian adenocarcinomas and found at high levels in patients with the worst outcome [41, 42]. The EF2 showed O-glycosidically linked glycans containing GlcNAc $\alpha 1,0 \mathrm{Ser} / \mathrm{Thr}$ and has been identified in melanoma and gastrointestinal cancers; it promotes $\mathrm{G} 2 / \mathrm{M}$ progression and enhances cell growth $[43,44]$. The beta actin is a $42 \mathrm{kDa}$ protein, and the actin network seems to play a relevant role in nuclear reorganization in breast cancer cells [45]. The NetOGlyc 3.1 server (www.cbs.dtu.dk/services/netoglyc) was used to predict the potential of O-glycosylation of the proteins recognized by MeA [46]. During cancer progression, polarized epithelial tumor cells convert into motile mesenchymal cells, invade the basement membrane, enter blood vessels, and disseminate into secondary organs [47]. The initial stage of these processes is associated with morphological changes referred to as epithelial-mesenchymal transition [48]. We suggest the possibility that increased expression of O-glycosidically-linked proteins, recognized by the lectin MeA, could result in an upregulation of specific mucin-type glycosyl-transferases [20, 49], and could participate in the disassembly of intercellular junctions as well as in increased cell motility favoring the disruption of intracellular adhesion junctions and cancer progression [50-53]. The possibility that MeA receptors represent an alternative new tool in the diagnosis of cervicouterine cancer, or potential biomarkers for cancer risk, or a target for drug delivery, should not be ruled out.

\section{Acknowledgments}

This article is part of the requirements to obtain the $\mathrm{PhD}$ of C.S. in the Doctoral Program in Medical and Biological Sciences, UABJO, Oaxaca, Mexico. This project was in part supported by CONACYT $(0113815$ and 0129932), and the Programa Universitario de Epidemiología, Genómica y Proteómica (SDEI.PTID.05.2), UNAM, Mexico. Thanks are due to M. Ali Pereyra, America Gutierrez, Daniel Montante, and Ana Ordońes (Facultad de Medicina, UNAM) for help in the preparation of this work.

This work is dedicated in loving memory of Guillermo Mendoza-Hernández.

\section{References}

1. Brockhausen I. Pathways of O-glycan biosynthesis in cancer cells. Biochim Biophys Acta. 1999;1473: 67-95.

2. HakomoriS. Glycosylation defining cancer malignancy: New wine in an old bottle. Proc Natl Acad Sci USA. 2002;99:10231-10233.

3. Kreunin P, Zhao J, Rosser C, Urquidi V, Lubman DM, Goodison $\mathrm{S}$. Bladder cancer associated glycoprotein signatures revealed by urinary proteomic profiling. J Proteome Res. 2007;6:2631-2639. 
4. Higai K, Ishihara S, Matsumoto K. NFkappaB-p65 dependent transcriptional regulation of glycosyltransferases in human colon adenocarcinoma HT-29 by stimulation with tumor necrosis factor alpha. Biol Pharm Bull. 2006;29: 2372-2377.

5. Gu C, Oyama T, Osaki T et al. Low expression of polypeptide GalNAc N-acetylgalactosaminyl transferase-3 in lung adenocarcinoma: impact on poor prognosis and early recurrence. Br J Cancer. 2004;90:436-442.

6. Blonski K, Milde-Langosch K, Bamberger AM et al. Ulex europeus agglutinin-I binding as a potential prognostic marker in ovarian cancer. Anticancer Res. 2007;27:2785-2790.

7. Dwek MV, Jenks A, Leathem AJ. A sensitive assay to measure biomarker glycosylation demonstrates increased fucosylation of prostate specific antigen (PSA) in patients with prostate cancer compared with benign prostatic hyperplasia. Clin Chim Acta. 2010; 411:1935-1939.

8. Metoki R, Kakudo K, Tsuji Y, Teng N, Clausen H, Hakomori S. Deletion of histo-blood group A and B antigens and expression of incompatible A antigen in ovarian cancer. J Natl Cancer Inst. 1989;81:1151-1157.

9. Chammas R, Sonnenburg JL, Watson NE et al. De-N-acetylgangliosides in humans: unusual subcellular distribution of a novel tumor antigen. Cancer Res. 1989;59:1337-1346.

10. Couldrey C, Green JE. Metastases: the glycan connection. Breast Cancer Res. 2000;2:321-323.

11. Gorelik E, Galili U, Raz A. On the role of cell surface carbohydrates and their binding proteins (lectins) in tumor metastasis. Cancer Metastasis Rev. 2001;20:245-277.

12. Springer GF. T and Tn pancarcinoma markers: autoantigenic adhesion molecules in pathogenesis, prebiopsy carcinoma-detection, and long-term breast carcinoma immunotherapy. Crit Rev Oncogenesis. 1995;6:57-85.

13. Lis H, Sharon N. Lectins as molecules and as tools. Ann Rev Biochem. 1986;55:35-67.

14. Santaella A, Gallegos B, Perez-Campos E, Zenteno E, Hernández P. Use of Amaranthus leucocarpus lectin to differentiate cervical dysplasia (CIN). Prep Biochem Biotechnol. 2007;37:219-228.

15. Kohrenhagen N. Volker HU, Kapp M, Dietl J, Kammerer U. Increased expression of galectin-1 during the progression of cervical neoplasia. Int J Gynecol Cancer. 2006;16:2018-2022 .

16. Zenteno E, Ochoa JL. Isolation and characterization of Amaranthus leucocarpus lectin. Phytochemistry. 1998;27:313-317.

17. Zenteno E, Debray H, Montreuil J. Purification and partial characterization of two lectins from the cactus Machaerocereus eruca. FEBS Letters. 1988;238:95-100.

18. Savage D, Mattson G, Desai S, Nielander G, Morgensen S, Coklin E. Avidin-biotin chemistry: a handbook. Rockford IL Pierce Chemical Co.; 1992.

19. Zenteno E, Vazquez L, Chavez R et al. Specificity of the isolectins from the plant cactus Machaerocereus eruca for oligosaccharides from porcine stomach mucin. Glycoconj $J$. 1995;12:699-706.

20. Mayoral MA, Mayoral C, Rembao D et al. Identification of Galectin-3 and Mucin-type O-glycans in breast cancer and its metastasis to brain. Cancer Invest. 2008;26:615-623.

21. Towbin M, Staehelin T, Gordon J. Electrophoretic transfer of proteins from polyacrilamide gels to nitrocellulose sheets: Procedure and some applications. Proc Natl Acad Sci USA. 1979;76:4350-4354.

22. Peterson GL. A simplification of the protein assay method which is more generally applicable. Anal Biochem. $1977 ; 83: 346-356$
23. Findlay JBC, Pappin D, Keen J. Automated solid-phase micro sequencing. In Finldaly (Ed), Protein sequencing, JBC 1989. IRL Press-Oxford University Press UK.

24. López-Ferrer A, Barranco C, de Bolos C. Differences in the O-glycosylation patterns between lung squamous cell carcinoma and adenocarcinoma. Am J Clin Pathol. 2002;118:749-755.

25. Van den Steen P, Rudd PM, Dwek RA, Openakker G. Concepts and principles of O-linked glycosylation. Crit Rev Biochem Mol Biol. 1988;33:151-208.

26. Martensson S, Levery SB, Fang TT, Bendiak B. Neutral core oligosaccharides of bovine submaxillary mucin: use of lead tetraacetate in the cold for establishing branch positions. Eur J Biochem. 1998;258:603-622.

27. Lotan R, Skutelsky E, Danon D, Sharon N. The purification, composition and specificity of the anti-T lectin from peanut (Arachis hypogaea). J Biol Chem. 1975;250: $8518-8523$.

28. Hernandez P, Tetaert D, Vergoten G et al. Specificity of Amaranthus leucocarpus syn hypocondriacus lectin for O-glycopeptides. Biochim Biophys Acta. 2004;1674:282-290.

29. Weiss I, Drickramer K. Structural basis of the lectin-carbohydrate recognition. Annu Rev Biochem. 1996; 65:441-473.

30. Sharma V, Surolia A. Analysis of carbohydrate recognition by legume lectin: Size of the combining site loops and their primary specificity. J Mol Biol. 1997;267:433-445.

31. Vijayan M, Chadra N. Lectins. Curr Op Struc Biol. 1999;9:704-714.

32. Clausen $\mathrm{H}$, Hakomori S. ABH and related histo-blood group antigens; immunochemical differences in carrier isotypes and their distribution. Vox Sang. 1989;56:1-20.

33. Laferte S, Chan NW, Sujino K, Lowary TL, Palcic MM. Intracellular inhibition of blood group A glycosyltransferase. Eur J Biochem. 2000;267:4840-4849.

34. Wang PH, Lee WL, Lee YR et al. Enhanced expression of a 2,6-sialyltransferase ST6Gal I in cervical squamous cell carcinoma. Gynecol Oncology. 2003;89:395-401.

35. Hernandez L, Roux KJ, Wong ES. Functional coupling between the extracellular matrix and nuclear lamina by Wnt signaling in progeria. Dev Cell. 2010;19:41-425.

36. Dey P. Nuclear margin irregularity and cancer: a review. Anal Quant Cytol Histol. 2009;31:345-352.

37. Han CP, Lee MY, Tyan YS et al. p16 INK4 and CEA can be mutually exchanged with confidence between both relevant three-marker panels (ER/Vim/CEA and ER/Vim/p16 INK4) in distinguishing primary endometrial adenocarcinomas from endocervical adenocarcinomas in a tissue microarray study. Vimentin Virchows Arch. 2009;455:353-361.

38. Lee MY, Chou CY, Tang MJ, Shen MR. Epithelial-mesenchymal transition in cervical cancer: correlation with tumor progression, epidermal growth factor receptor overexpression, and snail up-regulation. Clin Cancer Res. 2008;14:4743-4750 .

39. Stewart CJ, Little L. Diagnostic value and implications of vimentin expression in normal, reactive and neoplastic endocervical epithelium. Pathology. 2010;42:217-223.

40. Korita PV, Wakai T, Ajioka Y et al. Aberrant expression of vimentin correlates with dedifferentiation and poor prognosis in patients with intrahepatic cholangiocarcinoma. $A n$ ticancer Res. 2010;30:2279-2285.

41. Sahab ZJ, Hall MD, Zhang L, Cheema AK, Byers SW. Tumor Suppressor RARRES1 regulates DLG2, PP2A, VCP, EB1, and Ankrd26. J Cancer. 2010;1:4-22.

42. Scurr LL, Guminski AD, Chiew YE et al. Ankyrin repeat domain 1, ANKRD1, a novel determinant of cispl- 
atin sensitivity expressed in ovarian cancer. Clin Cancer Res. 2008;14:6924-6932.

43. Lee MY, Chou CY, Tang MJ, Shen MR. Epithelial-mesenchymal transition in cervical cancer: correlation with tumor progression, epidermal growth factor receptor overexpression, and snail up-regulation. Clin Cancer Res. 2008;14:4743-4750 .

44. Bera TK, Saint Fleur A, Ha D et al. Selective POTE paralogs on chromosome 2 are expressed in human embryonic stem cells. Stem Cells Dev. 2008;17:325-332.

45. Chang KW, Yang PY, Lai HY, Yeh TS, ChenTC, Yeh CT. Identification of a novel actin isoform in hepatocellular carcinoma. Hepatol Res. 2006;36:33-39.

46. Julenius K, Mřlgaard A, Gupta R, Brunak S. Prediction, conservation analysis and structural characterization of mammalian mucin-type O-glycosylation sites. Glycobiology. 2005;15:153-164.

47. Suzuki A, Iizuka A, Komiyama M et al. Identification of melanoma antigens using a Serological Proteome Approach (SERPA). Cancer Genomics Proteomics. 2010;17:17-23.

48. Nakamura J, Aoyagi S, Nanchi I et al. Overexpression of eukaryotic elongation factor eEF2 in gastrointestinal cancers and its involvement in $\mathrm{G} 2 / \mathrm{M}$ progression in the cell cycle. Int J Oncol. 2009;34:1181-1189.

49. Ambrosino C, Tarallo R, Bamundo A et al. Identification of a hormone-regulated dynamic nuclear actin network associated with estrogen receptor alpha in human breast cancer cell nuclei. Mol Cell Proteomics. 2010;9:1352-1367.

50. Rajpert-De Meyts E, Poll SN et al. Changes in the profile of simple mucin-type O-glycans and polypeptide GalNAc-transferases in human testis and testicular neoplasms are associated with germ cell maturation and tumour differentiation. Virchows Arch. 2007;4:805-814.

51. Lee MY, Chou CY, Tang MJ, Shen MR. Epithelial-mesenchymal transition in cervical cancer: correlation with tumor progression, epidermal growth factor receptor overexpression, and snail up-regulation. Clin Cancer Res. 2008;14:4743-4750 .

52. Plattner VE, Wagner M, Ratzinger G, Gabor F, Wirth M. Targeted drug delivery: binding and uptake of plant lectins using human 5637 bladder cancer cells. Eur J Pharm Biopharm. 2008;70:572-576.

53. Liu FT, Rabinovich GA. Galectins as modulators of tumour progression. Nat Rev Cancer. 2005;5:29-41.

Submitted: 29 April, 2011

Accepted after reviews: 26 January, 2012 